\title{
A influência dos hormônios sexuais na resposta imunológica da COVID- 19: uma revisão integrativa
}

The influence of sex hormones on the immune response of COVID-19: an integrative review

La influencia de las hormonas sexuales en la respuesta inmune de COVID-19: una revisión integradora

Dandara Meira dos Reis ${ }^{1 *}$, Larissa Pôrto Silva Ribeiro Gama ${ }^{2}$, Isadora Alves Teixeira ${ }^{1}$, Fernanda Gabriela Pereira de Paula ${ }^{1}$, Nathália Nascimento Ferreira ${ }^{3}$, Rege Farias Oliveira ${ }^{1}$, David César Louzada Álvares Macedo ${ }^{4}$, Maria Isabel Ramos Bahia', Clarissa Leal Silva e Souza'.

\section{RESUMO}

Objetivo: Avaliar as diferenças sexuais na resposta imunológica a COVID-19 relacionadas a influência hormonal. Métodos: Foi realizada uma pesquisa bibliográfica, de caráter exploratório, do tipo revisão integrativa de literatura. A busca dos artigos foi realizada nas bases eletrônicas de dados PubMed, Biblioteca Virtual em Saúde (BVS) e Scientific Electronic Libray Online (SciELO) no período de fevereiro a maio de 2021. Foram incluídos artigos originais, publicados entre 2020 e 2021 e redigidos em português, inglês ou espanhol. Excluíram-se qualquer publicação que não fosse artigo científico original, completo e que se distanciou da discussão. Resultados: O estrogênio diminui a expressão do receptor da enzima conversora da angiotensina 2 (ECA2), enquanto a testosterona aumenta a expressão em células do músculo liso das vias aéreas. Os andrógenos regulam a expressão dos receptores de ECA2, superfície celular transmembrana protease serina 2 (TMPRSS2) e receptor de andrógeno (RA) em células epiteliais pulmonares. As concentrações de testosterona são inversamente associadas à gravidade da doença e concentrações de citocinas inflamatórias circulantes em homens. Considerações finais: Os hormônios sexuais atuam na resposta imunológica tendo grande influência na disparidade sexual existente na vulnerabilidade e mortalidade da COVID-19, sendo que hormônios sexuais femininos atuam como fator protetivo contra infecção por SARS-CoV-2.

Palavras-chave: COVID-19, Hormônios sexuais, Diferenças sexuais, Resposta imunológica.

\begin{abstract}
Objective: To evaluate sex differences in immune response to COVID-19 related to hormonal influence. Methods: A bibliographical, exploratory research, integrative review type was carried out. The search for articles was performed in the electronic databases PubMed, Biblioteca Virtual em Saúde (BVS) and Scientific Electronic Libray Online (SciELO) from February to May 2021. Original articles, published between 2020 and 2021 and written in Portuguese, English or Spanish were included. Any publication that was not an original scientific article was excluded, complete scientific article and that distanced itself from the discussion was excluded. Results: Estrogen decreases the expression of the angiotensin converting enzyme 2 (ACE2) receptor, while testosterone increases expression in airway smooth muscle cells. Androgens regulate the expression of ACE2 receptors, cell surface transmembrane protease serine 2 (TMPRSS2) and androgen receptor (RA) on lung epithelial cells. Testosterone concentrations are inversely associated with disease severity and circulating inflammatory cytokine concentrations in men. Final considerations: Sex hormones act on the immune response, having a great influence on the existing gender disparity in the vulnerability and mortality of COVID-19.
\end{abstract}

Keywords: COVID-19, Sex hormones, Sex differences, Immune response.

\footnotetext{
${ }^{1}$ Faculdade de Saúde Santo Agostinho (FASA), Afya Educacional, Vitória da Conquista - BA.

*E-mail:dandaramreis@hotmail.com

2 Centro Universitário Uniftc, Vitória da Conquista - BA.

${ }^{3}$ Centro Universitário Atenas (UNIATENAS), Paracatu - MG.

${ }^{4}$ Universidade Federal de Minas Gerais (UFMG), Belo Horizonte - MG.
} 


\section{RESUMEN}

Objetivo: Evaluar las diferencias de sexo en la respuesta inmune al COVID-19 relacionadas con la influencia hormonal. Métodos: Se realizó una investigación bibliográfica, de carácter exploratorio, del tipo revisión integradora de la literatura. La búsqueda de artículos se realizó en las bases de datos electrónicas PubMed, Biblioteca Virtual en Salud (BVS) y Scientific Electronic Libray Online (SciELO) de febrero a mayo de 2021. Artículos originales, publicados entre 2020 y 2021 y escritos en portugués, inglés o español. Se excluyó cualquier publicación que no fuera un artículo científico original, completo y que se distanciara de la discusión. Resultados: El estrógeno disminuye la expresión del receptor de la enzima convertidora de angiotensina 2 (ECA2), mientras que la testosterona aumenta la expresión en las células del músculo liso de las vías respiratorias. Los andrógenos regulan la expresión de los receptores ECA2, la proteasa transmembrana serina 2 de la superficie celular (TMPRSS2) y el receptor de andrógenos (RA) en las células epiteliales pulmonares. Las concentraciones de testosterona están inversamente asociadas con la gravedad de la enfermedad y las concentraciones de citocinas inflamatorias circulantes en los hombres. Consideraciones finales: Las hormonas sexuales actúan sobre la respuesta inmune, teniendo una gran influencia en la disparidad de género existente en la vulnerabilidad y mortalidad del COVID-19.

Palabras clave: COVID-19, Hormonas sexuales, Diferencias sexuales, Respuesta inmune.

\section{INTRODUÇÃO}

A doença do coronavírus 2019 (COVID-19), responsável pela Síndrome Respiratória Aguda Grave (SARS), tem como agente o coronavirus-2 (SARS-CoV-2), um membro da família coronavírus que causou doenças como à Síndrome Respiratória do Oriente Médio (MERS) em 2012 e a Síndrome Respiratória Aguda induzida pela SRA-CoV em 2002. Declarada uma pandemia pela Organização Mundial da Saúde (OMS) em março de 2020. O aumento acentuado da infecção pelo SARS-CoV-2 e o alto impacto provocado no sistema de saúde, mesmo em países com estruturas médicas robustas, corroborou para que inúmeras pesquisas fossem realizadas com intuito de explorar melhor a patologia e quais fatores poderiam influenciar no prognóstico da doença (FORESTA C, et al., 2020).

Desde os primeiros relatos da COVID-19, pôde-se observar um impacto diferencial entre homens e mulheres. Dados epidemiológicos e clínicos indicam taxas de contaminação, gravidade e mortalidade quase duas vezes maior para homens do que para mulheres em todo o mundo (PATIL A, et al., 2020). Essas diferenças podem estar associadas a hábitos de vida como atividade física, alimentação, tabagismo, alcoolismo e comportamentos sociais que influenciam na saúde e assim, na suscetibilidade da infecção pelo SARS-CoV-2. Entretanto, inúmeros estudos apontam que as diferenças hormonais e imunológicas têm um papel crucial na fisiopatologia da COVID-19 influenciando na disparidade observada entre os sexos. As causas hormonais das diferenças sexuais culminam em dois divergentes sistemas biológicos entre homens e mulheres levando as diferenças existentes na predisposição e manifestação da doença (GADI N, et al., 2020).

A COVID-19 é uma infecção viral das vias aéreas que afeta principalmente as células dos alvéolos pulmonares, resultando na descamação de pneumócitos, formação e inflamação intersticial com infiltração de linfócitos. Os casos graves da infecção caracterizados pela SARS estão associados a respostas imunes inatas exageradas e retardadas, incluindo hipercitocinemia e infiltração de células inflamatórias nos pulmões. Essa hipercitocinemia e infiltração de monócitos e neutrófilos produz lesão pulmonar e dificuldades respiratórias presentes na doença (WRAY S e ARROWSMITH S, 2021).

Durante a doença, células imunes produzem a chamada "tempestade de citocinas", nos quais vão estar elevados os níveis séricos de citocinas, especificamente as interleucina-6 (IL-6), interleucina $1 \beta$ (IL-1 $\beta$ ), fator estimulador de colônias de granulócitos (G-CSF) e fator de necrose tumoral a (TNF- $\alpha$ ), citocinas que promovem a resposta imune e inflamatória através do recrutamento de neutrófilos e monócitos para o local da infecção. A partir disso, acredita-se que a tempestade de citocinas possua grande importância na progressão dos casos graves na COVID-19 (WRAY S e ARROWSMITH S, 2021). 
O vírus SARS-CoV-2 usa como ponto de entrada o receptor da enzima conversora de angiotensina 2 (ECA2) em células alvos, principalmente pneumócitos alveolares do tipo 2. Além disso, para estabelecimento da infecção, as glicoproteínas $S$ devem ser ativadas pela protease serina protease transmembrana 2 (TMPRSS2) da célula hospedeira, favorecendo a entrada viral (PIVONELLO R, et al., 2020). Assim, os mecanismos que regulam a expressão e funcionalidade da ECA2 e transcrição da TMPRSS2 têm a capacidade de influenciar na evolução e nos resultados da COVID-19 (WOLFE J, et al., 2021).

Atualmente, sabe-se que tanto o sexo quanto o gênero impactam na patogênese das doenças infecciosas. De um modo geral, tanto a intensidade (ou seja, a carga microbiana presente) quanto a prevalência das infecções são mais altas em homens do que em mulheres. (POTLURI, et al., 2017)

Os hormônios sexuais possuem uma influência significativa no controle e desenvolvimento da resposta imunológica no organismo. Ao exercerem suas ações por meio de receptores nucleares e de membrana são capazes de alterar o fluxo membranar e a expressão de genes e proteínas que medeiam diversos mecanismos celulares (AMGALAN A, et al., 2020). O estrogênio e a progesterona são hormônios esteroides presentes em maior quantidade nas mulheres, enquanto a testosterona, um dos principais andrógenos conhecidos, possui níveis mais elevados nos homens (GARGAGLIONI LH e MARQUES DA, 2020). Enquanto a testosterona é conhecida pelo seu papel imunossupressor geral, o estrogênio pode aumentar ou diminuir a resposta imunológica no organismo, com base em sua concentração, distribuição e expressão de seus receptores (RAZA HA, et al., 2021).

Diante disso, baseado nas diferenças hormonais e no papel dos esteroides sexuais no sistema imunológico, a literatura aponta diferenças marcantes entre os sexos no desfecho de diversas infecções existentes. Mediado principalmente pelo efeito protetor do estrogênio, o sistema imunológico feminino desenvolve uma resposta imune inata e adaptativa mais elevada e eficiente comparada aos homens nas infecções virais (GARGAGLIONI LH e MARQUES DA, 2020). As mulheres possuem níveis mais elevados de imunoglobulinas IgM e IgG circulantes. Assim, desenvolvem duas vezes mais títulos de anticorpos protetores após vacinas como influenza, hepatite, sarampo e febre amarela. Além disso, as mulheres também possuem frequências mais altas de células T auxiliares CD4+ e CD8+ do que os homens (LAMI RAA, et al., 2020).

Com isso, em comparação com os homens as mulheres demostram uma proteção contra uma variedade de doenças virais. Em infecções por HIV, estudos demonstraram que as mulheres têm contagens de CD4+ mais altas e ativação mais fortes de células T CD8+, juntamente com reduzidas cargas virais, relacionadas ao aumento da detecção viral inata (JARVIS FM, et al., 2020). Associado a isso, há fortes evidências que os estrogênios são responsáveis por inibirem a patogênese na doença óssea metabólica e na doença hepática induzida por vírus por meio da supressão da produção de IL-6. O hormônio impede a transcrição e produção do gene IL-6. Além disso, a incidência de carcinoma hepatocelular ( $\mathrm{CHC}$ ) induzido por hepatite $\mathrm{B}$ crônica em humanos foi correlacionado com concentrações de testosterona e mostra uma forte predominância no sexo masculino (FORESTA C, et al., 2020).

Ademais, estudos relataram que os estrogênios diminuem a regulação do receptor ECA-2 envolvido na patologia da COVID-19, que como citado anteriormente, é utilizado pelo vírus como ponto de entra nas células alveolares. Foi apontado ainda que a testosterona pode desempenhar um papel regulador positivo levando ao aumento da expressão de TMPRSS2, que por sua vez favorece a entrada viral de SARS-CoV-2, sugerindo que a testosterona pode ser um fator que induz na quantidade de casos mais elevados de mortalidade na infecção em homens em comparação com as mulheres (LIPSA A e PRABHU JS, 2021).

Associada as ações hormonais, alguns fatores genéticos podem influenciar na menor predisposição da COVID-19 no sexo feminino. As mulheres desfrutam do benefício genético de dois cromossomos $X$ responsáveis por codificar a maioria dos genes reguladores imunológicos existentes. Em contrapartida, os homens possuem apenas um cromossomo X, não tendo a mesma proteção (LAMI RAA, et al., 2020).

Sabe-se que a atual pandemia é responsável por consequências irreversíveis que impactaram inúmeras vidas na sociedade, mas as discrepâncias nas taxas de mortalidade em relação ao sexo são evidentes, e sugerem uma proteção significativa para o sexo feminino. Desse modo, é fundamental o conhecimento dos 
padrões da doença, dos fatores protetores existentes e dos fatores de risco que podem influenciar na infecção. Diante do exposto, o objetivo dessa revisão integrativa da literatura foi avaliar as diferenças baseadas nos principais hormônios sexuais, estrógeno e testosterona, na resposta imunológica contra o SARS-CoV-2 para demonstrar uma explicação plausível para disparidade de sexo existente nas taxas de vulnerabilidade, gravidade e mortalidade na COVID-19.

\section{MÉTODOS}

Esse estudo trata-se de uma pesquisa bibliográfica, de caráter exploratório, do tipo revisão integrativa da literatura. Para alcançar o objetivo do estudo foi elaborada a seguinte pergunta norteadora: "Qual é a influência que os hormônios sexuais exercem na resposta imunológica a COVID-19?". Neste estudo foram utilizados artigos encontrados nas principais bases eletrônicas de dados, como PubMED, Biblioteca Virtual em Saúde (BVS) e Scientific Electronic Libray Online (SciELO), conforme ilustrudado na Figura 1. A busca ocorreu entre os meses de fevereiro a abril de 2021 com utilização do operador booleano AND e das seguintes palavras-chave, inclusas nos Descritores em Ciências da Saúde (DeCS): "COVID-19" AND "Hormônios sexuais" e seus equivalentes na língua inglesa "COVID-19" AND “ Sex Hormones”.

Figura 1 - Fluxograma representativo da metodologia de inclusão dos artigos neste estudo.
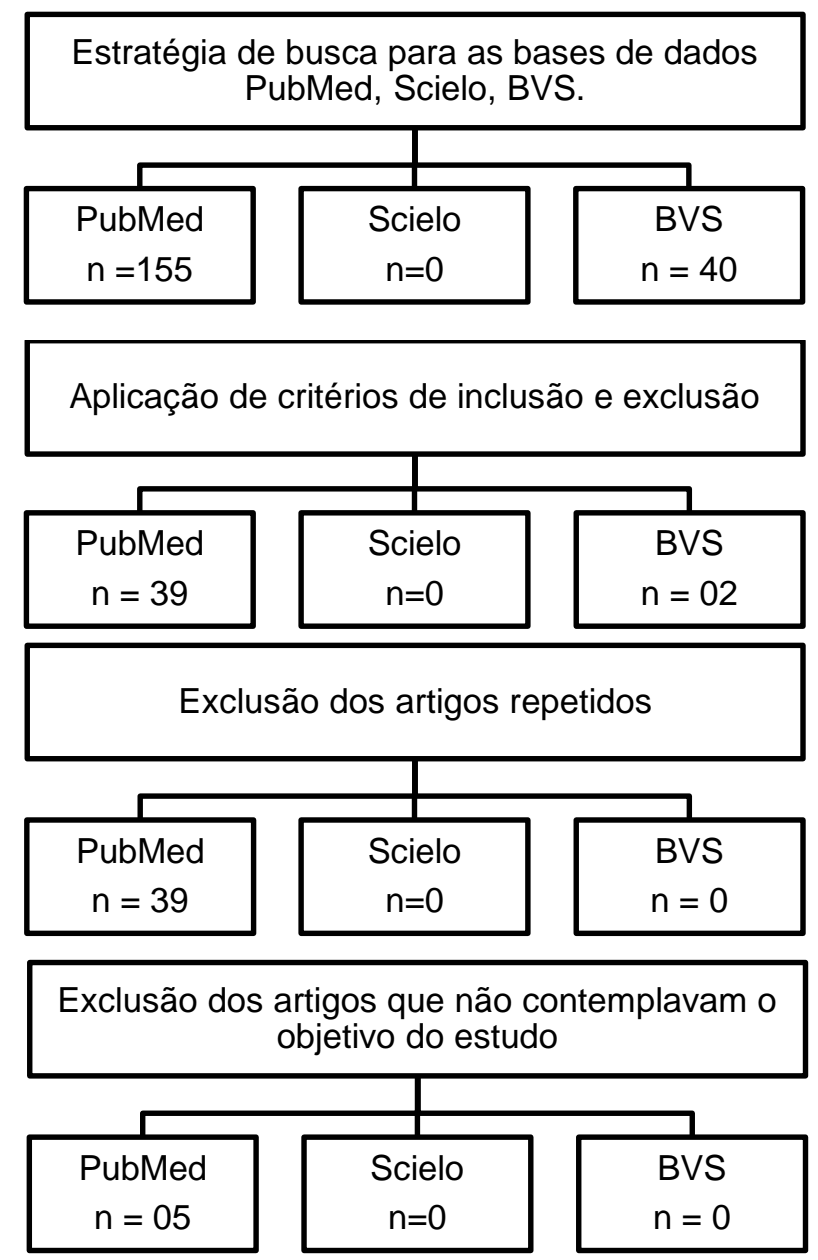

Número de artigos considerados para análise na revisão $=05$

Fonte: Reis DM, et al., 2021. 
Como critérios de inclusão para a construção da pesquisa foram selecionados artigos originais com texto integral, indexados nas bases eletrônicas de dados supracitadas compatível com no mínimo um dos objetivos da pesquisa, redigidos em português, inglês ou espanhol e publicados no ano entre 2020 e 2021.

Excluíram-se artigos de revisão de literatura, artigos de opinião, relatos de casos, cartas ao editor. Ademais foram excluídos artigos cujo objeto central se distanciou da discussão sobre a influência dos hormônios sexuais na resposta imunológica a COVID-19. No caso de artigos duplicados, presentes em mais de uma base de dados, um deles foi descartado.

Após realizada a aplicação dos critérios de inclusão e exclusão, foi efetuado a leitura do título e resumo dos artigos previamente selecionados e, após verificação da elegibilidade, foram selecionados cinco (05) artigos para análise deste estudo. Foram analisados o periódico em que o estudo foi publicado, os objetivos, a metodologia utilizada e as evidências produzidas.

\section{RESULTADOS}

No Quadro 1, os estudos selecionados foram listados em ordem cronológica de publicação, com ano de publicação, autores, nome do artigo, e periódico em que o estudo foi publicado.

Quadro 1 - Artigos selecionados de acordo com ano de publicação e periódico científico.

\begin{tabular}{|c|c|c|}
\hline Autores & Título do artigo & Periódico \\
\hline $\begin{array}{l}\text { KALIDHINDI RSR, et al., } \\
2020 .\end{array}$ & $\begin{array}{l}\text { Os esteroides sexuais distorcem a } \\
\text { expressão de ECA2 nas vias aéreas } \\
\text { humanas: um fator que contribui para as } \\
\text { diferenças sexuais no COVID-19? }\end{array}$ & AJP-Lung Cell Mol Physiol \\
\hline $\begin{array}{l}\text { RASTRELLI G, et al., } \\
2020 .\end{array}$ & $\begin{array}{l}\text { Níveis baixos de testosterona predizem } \\
\text { resultados clínicos adversos em pacientes } \\
\text { com pneumonia por SARS-CoV-2 }\end{array}$ & Andrology wiley \\
\hline QIAO Y, et al., 2020. & $\begin{array}{l}\text { Mirando a regulação da transcrição dos } \\
\text { fatores de entrada ECA2 e TMPRSS2 do } \\
\text { SARS-CoV-2 }\end{array}$ & PNAS \\
\hline CAMICIA M, et al., 2021. & $\begin{array}{l}\text { Papel da testosterona na infecção por } \\
\text { SARS-CoV-2:um fator patogênico chave e } \\
\text { um biomarcador para pneumonia grave }\end{array}$ & $\begin{array}{l}\text { International Journal of } \\
\text { Infectious Diseases }\end{array}$ \\
\hline $\begin{array}{c}\text { DHINDSA S, et al., } \\
2021 .\end{array}$ & $\begin{array}{l}\text { Associação de hormônios sexuais } \\
\text { circulantes com inflamação e gravidade da } \\
\text { doença em pacientes com COVID-19 }\end{array}$ & JAMA Network Open \\
\hline
\end{tabular}

Fonte: Reis DM, et al., 2021.

O Quadro 2 ilustra a metodologia de cada estudo selecionado, além dos objetivos e evidências produzidas. Os resultados apresentados são de acordo com o hormônio avaliado. No que diz respeito à metodologia adotada, verificou-se um estudo de coorte, um estudo de caso controle e três não mencionadas. Foi possível localizar ou inferir, em todos os artigos selecionados, os objetivos propostos e as evidências produzidas a partir da pesquisa ou dos argumentos apresentados. 
Quadro 2 - Distribuição dos artigos selecionados, observando-se os seguintes aspectos: objetivos, metodologia e evidências produzidas.

\begin{tabular}{|c|c|c|c|c|}
\hline Autores & Título & Objetivo(s) & Metodologia & Evidências \\
\hline \multicolumn{5}{|c|}{ Hormônios Avaliados: Estrogênio e Testosterona } \\
\hline $\begin{array}{l}\text { KALIDHINDI RSR, et al., } \\
2020 .\end{array}$ & $\begin{array}{l}\text { Os esteroides sexuais distorcem a } \\
\text { expressão de ECA2 nas vias } \\
\text { aéreas humanas: um fator que } \\
\text { contribui para as diferenças sexuais } \\
\text { no COVID-19? }\end{array}$ & $\begin{array}{l}\text { Explorar o efeito do estrogênio versus } \\
\text { testosterona na modulação da } \\
\text { expressão da enzima conversora da } \\
\text { angiotensina } 2 \text { (ECA) em células do } \\
\text { músculo liso das vias aéreas } \\
\text { humanas. }\end{array}$ & Não mencionada & $\begin{array}{l}\text { 1- A ECA2 é expressa em músculo liso das vias } \\
\text { aéreas humanas (MLVA); } \\
\text { 2- A ECA2 tem menor expressão de base na } \\
\text { MLVA de mulheres em comparação com } \\
\text { homens; 3- O estrogênio reduz a expressão } \\
\text { da ECA2, enquanto a testosterona aumenta } \\
\text { ECA2 em células MLVA humanas. }\end{array}$ \\
\hline $\begin{array}{l}\text { DHINDSA S, et al., } \\
2021 .\end{array}$ & $\begin{array}{l}\text { Associação de hormônios sexuais } \\
\text { circulantes com inflamação e } \\
\text { gravidade da doença em pacientes } \\
\text { com COVID-19. }\end{array}$ & $\begin{array}{l}\text { Investigar a associação das } \\
\text { concentrações de testosterona } \\
\text { sérica, estradiol e fator de } \\
\text { crescimento } 1 \text { semelhante a insulina } \\
\text { (IGF-1) com a gravidade da COVID- } \\
19 .\end{array}$ & $\begin{array}{l}\text { Estudo de coorte } \\
\text { monocêntrico }\end{array}$ & $\begin{array}{l}\text { 1- Entre } 152 \text { pacientes com COVID-19, } \\
\text { incluindo } 143 \text { pacientes hospitalizados, as } \\
\text { concentrações de testosterona na } \\
\text { apresentação e no dia } 3 \text { estavam } \\
\text { inversamente associadas à gravidade da } \\
\text { doença e concentrações de citocinas } \\
\text { inflamatórias circulantes em homens, mas } \\
\text { não em mulheres; } \\
\text { 2- } 0 \text { perfil transcricional das células } \\
\text { mononuclerares revelou uma regulação } \\
\text { positiva das vias de sinalização hormonal em } \\
\text { pacientes que necessitavam de cuidados } \\
\text { intensivos versus aqueles com doença mais } \\
\text { branda. }\end{array}$ \\
\hline \multicolumn{5}{|c|}{ Hormônio Avaliado: Testosterona } \\
\hline $\begin{array}{l}\text { RASTRELLI G, et al., } \\
2020\end{array}$ & $\begin{array}{l}\text { Níveis baixos de testosterona } \\
\text { predizem resultados clínicos } \\
\text { adversos em pacientes com } \\
\text { pneumonia por SARS-CoV-2. }\end{array}$ & $\begin{array}{l}\text { Estimar a associação entre o nível } \\
\text { Testosterona e os resultados clínicos } \\
\text { da SRA-CoV-2. }\end{array}$ & Não mencionada & $\begin{array}{l}\text { 1- Níveis mais baixos de testosterona total (TT) } \\
\text { e testosterona livre calculada (TELIC) são } \\
\text { preditores de mau prognóstico em homens } \\
\text { com SRA-CoV-2 admitidos por pneumonia; } \\
\text { 2- Destaca-se a relação longitudinal entre } \\
\text { menores níveis de TT e TELIC e um maior } \\
\text { risco de deterioração clínica, levando à } \\
\text { transferência para a UTI ou à morte; } \\
\text { 3- Baixos níveis de TT e TELIC estão } \\
\text { significativamente associados a LDH, } \\
\text { ferritina, PCT, bem como a um aumento do } \\
\text { nível de neutrófilos e diminuição da contagem } \\
\text { de linfócito. }\end{array}$ \\
\hline
\end{tabular}




\begin{tabular}{|c|c|c|c|c|}
\hline Autores & Título & Objetivo(s) & Metodologia & Evidências \\
\hline \multicolumn{5}{|c|}{ Hormônios Avaliados: Estrogênio e Testosterona } \\
\hline QIAO Y, et al., 2020. & $\begin{array}{l}\text { Mirando a regulação da transcrição } \\
\text { dos fatores de entrada ECA2 e } \\
\text { TMPRSS2 do SARS-CoV-2. }\end{array}$ & $\begin{array}{l}\text { Determinar quais células do trato das } \\
\text { vias aéreas superiores expressam } \\
\text { enzima conversora de angiotensina } 2 \\
\text { (ECA2) e a superfície celular } \\
\text { transmembrana protease serina } \\
\text { 2(TMPRSS2) e testar se suas } \\
\text { expressões poderiam ser } \\
\text { terapeuticamente direcionadas por } \\
\text { inibidores de receptor de androgênio } \\
\text { usados no tratamento do câncer de } \\
\text { próstata. }\end{array}$ & Não mencionada & $\begin{array}{l}\text { 1- Os andrógenos regulam a expressão dos } \\
\text { receptores de enzima conversora de } \\
\text { angiotensina } 2 \text { (ECA2) e a superfície celular } \\
\text { transmembrana protease serina } 2 \\
\text { (TMPRSS2) e receptor de andrógeno (RA) } \\
\text { em subconjuntos de células epiteliais } \\
\text { pulmonares. } \\
\text { 2- Os níveis de RA são significativamente } \\
\text { elevados em machos em relação às fêmeas } \\
\text { com mais de } 70 \text { anos de idade. } \\
\text { 3- Em machos maiores de } 70 \text { anos, o tabagismo } \\
\text { foi associado a níveis elevados de RA e } \\
\text { ECA2 em células epiteliais pulmonares. } \\
\text { 4- A repressão transcricional do RA melhora o } \\
\text { anseio com antagonistas Ar ou bromodomí } \\
\text { e domínio extraterminal (BET) inibindo } \\
\text { infecção in-vitro pelo sars-cov-2. }\end{array}$ \\
\hline CAMICIA M, et al., 2021. & $\begin{array}{l}\text { Papel da testosterona na infecção } \\
\text { por SARS-CoV-2:um fator } \\
\text { patogênico chave e r um } \\
\text { biomarcador para pneumonia } \\
\text { grave. }\end{array}$ & $\begin{array}{l}\text { Investigar a associação entre os } \\
\text { hormônios sexuais e a gravidade da } \\
\text { doença coronavírus } 2019 \text { (COVID- } \\
\text { 19). }\end{array}$ & $\begin{array}{l}\text { Estudo de caso- } \\
\text { controle }\end{array}$ & $\begin{array}{l}\text { 1- Os pacientes com COVID-19 grave (casos) } \\
\text { tinham um nível significativamente menor de } \\
\text { testosterona em comparação com os } \\
\text { pacientes com COVID-19 leve (controles). } \\
\text { 2- A mediana da testosterona total (TT) foi de } \\
1,4 \mathrm{ng} / \mathrm{mL} \text { nos casos e } 3,5 \mathrm{ng} / \mathrm{mL} \text { nos } \\
\text { controles; a mediana da testosterona } \\
\text { biodisponível (BioT) foi de } 0,49 \text { e } 1,21 \text { nos } \\
\text { casos e controles; e a mediana da } \\
\text { testosterona livre calculada (cFT) foi de } \\
0,029 \mathrm{ng} / \mathrm{mL} \text { e } 0,058 \mathrm{ng} / \mathrm{mL} \text { em casos e } \\
\text { controles. } \\
\text { 3- Não foi encontrada associação entre o nível } \\
\text { de hormônio sexual e a duração da descarga } \\
\text { viral, ou entre o nível de hormônio sexual e a } \\
\text { taxa de mortalidade. }\end{array}$ \\
\hline
\end{tabular}

Fonte: Reis DM, et al., 2021. 


\section{DISCUSSÃO}

Evidências clínicas e epidemiológicas apontam disparidades relacionadas ao sexo na incidência, gravidade e mortalidade da COVID-19. Os homens são desproporcionalmente afetados em relação às mulheres, o que pode indicar a influência dos hormônios sexuais na fisiopatologia da COVID-19 (KALIDHINDI RSR, et al., 2020). Os esteroides sexuais são imunomoduladores potentes e as diferentes concentrações de estrogênios, progesterona e testosterona podem ser um fator importante e não só impactar nas cargas virais, mas também moldar as manifestações clínicas, complicações da doença e mortalidade (JARVIS FM, et al., 2020)

O estrogênio é um esteroide envolvido em processos biológicos de diversos tecidos. Há três variedades de estrogênio presentes no organismo, sendo eles a estrona (E1), o 17ß-estradiol (E2) e o estriol (E3). O E1 é o hormônio que possui a menor influência no corpo e o nível do E3é extremamente baixo, sendo assim, o E2 se torna o mais potente dos três estrogênios existentes. Apesar de ser sintetizado no cérebro, nas glândulas supra-renais e nos testículos dos homens, o E2 é sintetizado principalmente nos ovários, sendo o principal hormônio sexual feminino. Assim, as mulheres possuem os níveis mais altos desse hormônio no organismo do que os homens. Com isso, para a maioria das doenças infecciosas, observa-se consistentemente que sexo feminino tende a desenvolver uma resposta imunológica mais forte e eficiente do que o sexo masculino (LI U, et al., 2020).

O receptor de estrogênio $\alpha$ (RE- $\alpha$ ) e receptor estrogênio $\beta$ (RE- $\beta$ ) são expressos em diferentes células do sistema linfático como linfócitos $B$ e linfócitos Te estão envolvidos em sua maturação e regulação. Os estrogênios são conhecidos pelo seu papel em recrutar monócitos, regular citocinas e na apresentação de antígenos. Além disso, por meio de seu receptor de sinalização, demonstrou promover o reconhecimento de padrões da produção de citocinas incluindo fator de necrose tumoral $\alpha$ (IFN- $\alpha$ ) antiviral por células dendríticas plasmocitoides (PATIL A, et al., 2020). Como importante regulador das células imunes, o aumento circulante desse hormônio afeta o sistema imunológico inato e adaptativo promovendo efeitos antiinflamatórios e neuroprotetores (PINNA G, 2021).

As ações antiinflamatórias de E2 na imunidade inata envolvem a supressão da produção de citocinas pró-

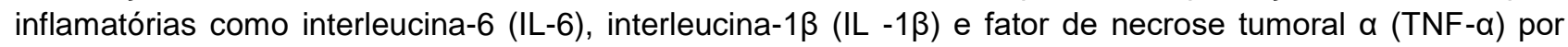
monócitos e macrófagos, envolvidas na tempestade de citocinas observada na COVID-19, e quimiocinas, como CCL2, diminuindo assim a migração de neutrófilos e monócitos para áreas inflamadas. Os níveis mais elevados de E2 também se correlacionam com níveis mais baixos de interleucina-2 (IL-2) e interleucina-8 (IL8) e diminuir a produção de citocinas pró-inflamatórias IL-12 de macrófagos ativados e IL-6 alterando diretamente monócitos CD16.Isso poderia indicar um possível papel protetor do estrogênio na prevenção da síndrome da tempestade de citocinas associada a COVID-19 (RAZA HA, et al., 2021).

Além disso, altas concentrações de estrogênio comumente favorecem respostas do tipo TH2 e estimula a produção de citocinas com atividade antiinflamatória como a interleucina-4 (IL-4) e interleucina-10 (IL-10). Apresenta, ainda, efeito acentuado na maturação, diferenciação e atividade dos linfócitos $B$ e promove tolerância imunológica por aumentar a expansão de células T reguladoras (Jarvis FM, et al., 2020). Ademais, além das interleucinas já mencionadas, pode haver estimulação de maiores concentrações de anticorpos, assim como das células envolvidas na sua produção contra a presença de infecções virais (JAKOVAC H, 2020).

O receptor da enzima conversora de angiotensina 2 (ECA2) é considerada o receptor funcional para SARSCoV-2. Diante disso, vale ressaltar que altas concentrações de estrogênios também diminuem a regulação do receptor de ECA, enquanto a redução do hormônio no organismo causa efeito contrário nos receptores, ou seja, aumentam sua expressão (HUSSAIN NA, et al., 2020). Assim, diante do papel do E2 na regulação, ativação das células do sistema imunológico e na expressão do receptor do ECA, destaca-se o papel fundamental do estrogênio na prevenção da síndrome da liberação de citocinas e redução da vulnerabilidade existentes em mulheres na COVID-19 (PRADHAN A e OLSSON PE, 2020).

Outro importante hormônio esteroide, a progesterona $(P)$, possui funções imunomoduladoras relevantes, como remodelar a competência das células imunológicas e estimular ações antiinflamatórias que poderiam 
mitigar a reação hiperinflamatória neutralizando o desenvolvimento da tempestade de citocinas. A progesterona pode inibir a interleucina pró- inflamatórias interleucina-1(IL-1), estimular a diferenciação das células $T$ reguladoras, restringir as respostas Th17 e aumenta as vias do interferon-alfa (IFN- $\alpha$ ) que, em conjunto, podem ser importantes para manter a replicação viral controlada e sem inflamação excessiva (JAKOVAC H, 2020).

Além disso, a progesterona se liga a receptores de progesterona em células imunes como as células $T$, macrófagos e células dendríticas e a células não imunes, epiteliais e endoteliais no trato respiratório tendo a capacidade de alterara atividade celular podendo assim, melhoras as infecções (PINNA G, 2021).

Um estudo recente no mapa de interação da proteína SARS-CoV-2 desvendou que a progesterona pode ter a capacidade de antagonizar os receptores Sigma do retículo endoplasmático que estão implicados na circulação montagem de componentes virais, ocasionalmente interrompendo a via endocítica explorada pelo SARS-CoV-2 (LIPSA A e PRABHU JS, 2021).

Nesse sentido, apesar de o hormônio ser negligenciado e pouco discutido comparado a outros hormônios existentes, os dados disponíveis apontam a relevância da progesterona nas diferenças sexuais imunológicas. Além disso, há evidências crescentes do seu papel protetor e eficácia, assim como a do estrogênio supramencionado na menor vulnerabilidade, mortalidade e gravidade na COVID-19 em mulheres infectadas (PINNA G, 2021).

Os andrógenos, sendo o principal deles a testosterona (T), assim como os estrogênios também possuem um efeito considerável na regulação do sistema imunológico. Estudos evidenciaram que testosterona pode diminuir a produção de citocinas como interferon-alfa (IFN- $\alpha$ ) e TNFa. Além disso, tem sido especulado que a testosterona pode suprimir células TH2 e Th17 e, portanto, afetam a resposta imune adaptativa. Esse hormônio também pode ser responsável pela redução do anticorpo em resposta as condições infecciosas e aumentar a produção de interleucinas (IL-1ß, IL-10, IL-2) podendo causar infecções graves em homens (JARVIS MF, ET AL., 2020).

A quantidade de testosterona produzida pelos homens é superior comparada as das mulheres. Enquanto o estrogênio possui funções imunoestimuladoras, a testosterona tem um papel imunossupressor e neutraliza as vias afetadas pelo E2. Como consequência disso, os homens produzem respostas imunológicas menos potentes e são mais suscetíveis a uma diversidade de agentes infecciosos (GARGAGLIONI LH e MARQUES DA, 2020).

De acordo com Kalidhindi RSR, et al. (2020), em um estudo em que foi explorado o efeito do estrogênio versus a testosterona na modulação da expressão da ECA2, células do músculo liso humano das vias aéreas (MLA) foram expostas aos dois hormônios separadamente pelo período de 24 horas e foi constatado que a testosterona aumenta consideravelmente a expressão de ECA2 em homens e mulheres, enquanto o estrogênio diminui a regulação de ECA2.

Além da ECA2, outros mecanismos estão envolvidos no aumento da suscetibilidade masculina. Qiao Y, et al. (2020) constatou que os andrógenos, produzidos pelos testículos, regulam a expressão de TMPRSS2 e que um ambiente privado de andrógeno leva à diminuição da expressão de TMPRSS2 e ECA2 em células epiteliais pulmonares.

Já em estudo realizado por Rastrelli G, et al. (2020) foi evidência do que a quantidade mais baixa de testosterona total (TT) e testosterona livre calculada (TLC) está relacionada com complicação clínica e morte em homens com SARS-CoV-2 admitidos em unidades de cuidados intensivos respiratórios por pneumonia. Com isso, foi demonstrado que baixas concentrações do hormônio testosterona são inversamente associadas a gravidade e concentrações de citocinas inflamatórias circulantes.

Diante disso, há maior parte das evidências indicam que o nível elevado da testosterona pode desempenhar um efeito regulador positivo na expressão de ECA2 e que é provável que contribua para elevada expressão de TMPRSS2, aumentando assim a entrada viral nas células, o que pode explicar a maior propensão dos homens comparado as mulheres em evoluir para forma mais grave da infecção por SARSCoV-2 e morte. 


\section{CONSIDERAÇÕES FINAIS}

Nesta revisão foram reunidas informações de alguns dos principais estudos que abordam as influências hormonais na resposta imunológica na COVID-19 para averiguar o possível motivo da diferença que envolve os sexos. A partir disso evidenciou-se que as mulheres, por apresentarem altos níveis de estrógeno e progesterona, desenvolvem uma resposta imunológica mais eficiente contra a maioria das infecções virais, além de diminuírem a expressão do receptor de ECA2 ponto de entrada do vírus SARS-CoV-2. Assim, neste estudo infere-se que os hormônios sexuais influenciam no sistema imunológico culminado para diferenças existentes entre os sexos na resposta a infecções e que hormônios femininos são um fator protetivo contra o SARS-CoV-2. No entanto, por ser uma doença recente uma das limitações desse estudo foi o número de estudos existentes clínicos e experimentais que abordem a influência dos hormônios sexuais na resposta imunológica a COVID-19 ainda serem baixos. Por isso, a realização de mais estudos é necessária para que as diferenças sexuais na COVID-19 sejam bem evidenciadas.

\section{REFERÊNCIAS}

1. AUERBACH JM, KHERA M. Testosterone's Role in COVID-19. J Sex Med, 2021; 18: 843-848

2. CAMICI M, et al. Role of testosterone in SARS-CoV-2 infection: A key pathogenic factor and a biomarker for severe pneumonia. International Journal of Infectious Diseases, 2021; 108: 244-251.

3. DHINDSA S, et al. Association of Sex Hormones With COVID-19 Inflammation and Disease Severity. JAMA Network Open, 2021; 4(5): e2111398.

4. FORESTA C, et al. Gender susceptibility to COVID-19: a review of the putative role of sex hormones and $X$ chromosome. Journal of Endocrinological Investigation, 2021; 44:951-956

5. FROLDI G, DORIGO P. Endothelial dysfunction in Coronavirus disease 2019 (COVID-19): Gender and age influences. Medical Hypotheses, 2020; 144:110015

6. GARGAGLIONI LH, MARQUES DA. Let's talk about sex in the context of COVID-19. J Appl Physiol, 2020; 128: 15331538.

7. HAZA HA, et al. Sex hormones, autoimmunity and gender disparity in COVID-19. Rheumatology International, 2021; $41: 1375-1386$

8. HUSSAIN NA, et al. Role of testosterone in COVID-19 patients - A double-edged sword?. Medical Hypotheses, 2020; 144: 110287.

9. JACOVAK H. Sex differences in COVID-19 course and outcome: progesterone should not be neglected. Journal of Applied Physiology, 2020; 129: 1007-1008

10. JARVIS MF, et al. Are sex discordant outcomes in COVID-19 related to sex hormones?. Seminars in Oncology, 2020; 47(5):335-340

11. KALIDHINDI RSR, et al.Sex steroids skew ACE2 expression in human airway: a contributing factor to sex differences in COVID-19?.Am J Physiol Lung Cell Mol Physiol, 2020; 319: L843-L847

12. LAMI RAA, et al. Sex Hormones and Novel Corona Virus Infectious Disease (COVID-19). Mayo Clin Proc, 2020; 95(8): 1710-1714

13. LIPSA A, PRABHU JS.Gender disparity in COVID-19: Role of sex steroid hormones. Asian Pacific Journal of Tropical Medicine, 2021; 14(1): 5-9

14. LI W, et al. Molecular mechanisms of sex bias differences in COVID-19 mortality. Critical Care, 2020; 24(1): 405

15. MORADI F, et al. The role of androgens in COVID-19. Diabetes \& Metabolic Syndrome: Clinical Research \& Reviews, 2020; 14(6): 2003-2006

16. PATIL A, et al. SeXX and COVID-19: tussle between the two. Monaldi Archives for Chest Disease, 2020; $90: 1461$

17. POTLURI T, et al. Sex Reporting in Preclinical Microbiological and Immunological Research. MBio, $2017 ; 8$ (6): e01868-17

18. PINNA G. Sex and COVID-19: A Protective Role for Reproductive Steroids. Trends in Endocrinology \& Metabolism ,2020; 161(9): bqaa127.

19. PIVONELLO R, et al. Sex disparities in covid-19 severity and outcome: are men weaker or women stronger?. Neuroendocrinology, 2020; 1-20

20. PRADHAN A, OLSSON PE. Sex differences in severity and mortality from COVID-19: are males more vulnerable?.Biol Sex Differ, 2020; 11: 53.

21. QIAO Y, et al. Targeting transcriptional regulation of SARS-CoV-2 entry factors ACE2 and TMPRSS2. PNAS, 2020; 118 (1): e2021450118.

22. RASTRELLI G, et al. Low testosterone levels predict clinical adverse outcomes in SARS-CoV-2 pneumonia patients. Andrology, 2020; 1-11.

23. VIGNERA SL, et al. Sex-Specific SARS-CoV-2 Mortality: Among Hormone-Modulated ACE2 Expression, Risk of Venous Thromboembolism and Hypovitaminosis D. International Journal of Molecular Sciences,2020; 21 (8): 2948.

24. WOLFE J, et al. Sex- or Gender-specific Differences in the Clinical Presentation, Outcome, and Treatment of SARSCoV-2. Clinical Therapeutics, 2021; 43 (3): 557-571.e1.

25. WRAY S, ARROWSMITH A. The Physiological Mechanisms of the Sex-Based Difference in Outcomes of COVID19 Infection. Front. Physiol, 2021; 12: 627260. 